\title{
The Seven Scam Types: Mapping the Terrain of Cybercrime
}

\author{
Amber Stabek, Paul Watters and Robert Layton \\ Internet Commerce Security Laboratory \\ University of Ballarat \\ Mt Helen, Australia \\ a.stabek@icsl.ballarat.edu.au,p.watters@icsl.ballarat.edu.au,r.layton@ballarat.edu.au
}

\begin{abstract}
Threat of cybercrime is a growing danger to the economy. Industries and businesses are targeted by cyber-criminals along with members of the general public. Since cybercrime is often a symptom of more complex criminological regimes such as laundering, trafficking and terrorism, the true damage caused to society is unknown. Dissimilarities in reporting procedures and non-uniform cybercrime classifications lead international reporting bodies to produce incompatible results which cause difficulties in making valid comparisons. A cybercrime classification framework has been identified as necessary for the development of an inter-jurisdictional, transnational, and global approach to identify, intercept, and prosecute cyber-criminals. Outlined in this paper is a cybercrime classification framework which has been applied to the incidence of scams. Content analysis was performed on over 250 scam descriptions stemming from in excess of 35 scamming categories and over 80 static features derived. Using hierarchical cluster and discriminant function analysis, the sample was reduced from over 35 ambiguous categories into 7 scam types and the top four scamming functions - identified as scamming business processes, revealed. The results of this research bear significant ramifications to the current state of scam and cybercrime classification, research and analysis, as well as offer significant insight into the business processes and applications adopted by scammers and cyber-criminals.
\end{abstract}

Keywords-Agglomerative, business process, classification, cybercrime, cyberscam, divisive, framework, static feature.

\section{INTRODUCTION}

Many organisations affected by cybercrime have their own incident classification systems that operate using an agglomerative approach which involves breaking down events in order to understand their components. While this is useful to the parent organisation, these do not translate across platforms to allow for multi-party adoption which means that collaboration between sectors is near impossible. In contrast to this, the cybercrime classification framework outlined in this paper offers a combined agglomerative - divisive methodology which reconstructs deconstructed events in order to understand its processes. Unlike current criminological approaches, the method applied in the cybercrime classification framework is designed to be multidisciplinary and adaptable across sectors.

The objective of this research is to determine a classification system that can be used by various parties to refer to similar types of scams in international cybercrime. Inconsistencies in the cybercrime lexicon have regularly been reported as a reason behind insubstantial cross border liaisons [1], [2] incongruent transnational cooperation and unsuccessful investigations leading towards increasing cybercrime incidents [3]. This in turn causes congestion of law enforcement and industry resources [3], [6].

A cybercrime classification framework $(\mathrm{CCF})$ would assist in formalising a language of cybercrime remaining consistent within jurisdictions and uniform across multi-national platforms. Such consistency would assist authorities by enhancing communication and cooperation between jurisdictions both at home and across national borders, as well as provide compatibility between cybercrime reporting agencies, allowing for a true representation of cybercrime incidence to be realised internationally.

By utilising the cybercrime classification framework outlined in this paper, 7 genres of scams were identified along with four primary scammer business processes. This information can be used by law enforcement agencies and dedicated cybercrime and fraud task forces in their identification, tracking and monitoring of cybercrimes and a contribution is made towards the utilisation of mixed methodologies for investigating cybercrime. This paper is divided into 6 subsequent sections; Motivation, where the motivation behind this research is discussed, Report Analysis, where an overview of cybercrime statistics and comparisons between reporting institutions and cybercrime research is presented, Methodology, where the methodology applied in this research is presented, Results, where the investigative results are detailed, Discussion, where a comprehensive discussion of the significance of the research and its results is considered, and Conclusion, where final remarks are made. 


\section{MOTIVATION}

Lack of uniformity and inconsistency in scam classification has been identified as an ongoing concern since the 1990's [1]. Strong evidence is presented [2] citing breadth of variation in scam classification among international and national scam reporting institutions, such as the Australian Bureau of Statistics (ABS), the Internet Crime Complaint Center (iC3), and the Environics Research Group (ERG). Further to this, large variation in scam classification is regularly identified as a primary cause of discrepancy in victim report data, and identified as an area in need of investigation [1], [2], [3], [4], [5]. These inconsistencies are reported as symptoms of ineffective scam identification and low rates of interception by law enforcement agencies resulting in the poor prosecution rates of scammers [6].

Confusion, uncertainty, and false negatives are the consequences of such discrepancy in scam classifications leading to more complex concerns, such as the under-reporting of scam incidence, reduced rates of successful follow up by investigative and law enforcement agencies and difficulty in making correct referrals [2], [6]. The blurred boundaries of scam classification are inherent throughout anti-fraud legislation, which the criminals seemingly exploit to their advantage [7]. While transnational investigative bodies dealing with the complexities of working beyond home borders and interacting with multiple jurisdictions face compounding challenges stemming from these issues [5], [6], [7].

During 1998 Glenn Wahlert from the Australian Federal Police (AFP) presented a paper at the Internet Crime Conference (ICC) where concerns surrounding the escalating adoption of computer technologies for business operations and personal use emerged [1]. During this time, technology based crimes were predominantly computer assisted crimes; these were crimes in which technology was the target of the attack, such as infecting an endusers machine with malicious code [1].

Wahlert [1] described technology based crimes beyond tech-as-target crimes by identifying areas of potential exploitation by cyber-criminals; the banking and finance sector, laundering, counterfeiting, trafficking, sexually related crimes, gambling, tactical intelligence, and scams [1]. Primary concerns surrounding the issues of anonymity, mass communicability, jurisdictional impedances, and cultural ambiguities were identified as high priority themes in need of committed research.

Effective mechanisms for the identification and monitoring of technology based crimes were identified as necessary for controlling technological exploitation. Further to this, it was suggested that the development of transnational agencies authorised to operate across jurisdictions were imperative to fight the phenomena [1].
The current lack of consistency in cyberscam classifications impede coordinated operations and make cross jurisdictional comparisons of scam incidence impossible [7], [2]. A cybercrime classification framework would aid in the detection, interception and prosecution of cyber-criminals.

The discrepancies between reporting institutions are briefly discussed in the next section

\section{REPORT ANALYSIS}

The iC3 2008 Internet Crime Report found that the reported incidence of cyberscams increased by $33.1 \%$ from 2007 [8]. Reports of scam incidence were recorded all throughout the United States with complaints received from as far abroad as Australia. Victim ages ranged from 10 years to 100 years and the total dollar loss was reported to be $\$ 264.6$ million, an increase of \$25.51 million from 2007 [8], [9].

The iC 3 only reports on cases where a monetary loss was recorded, and as such only recognises instances of fraud as those where a financial loss has been incurred. The assumption that fraud encompasses only a monetary disadvantage is not representative of the broad and complex nature of cybercrime. The IC3 identified seven types of scams stemming from nine different categories of complaint.

During 2008, the ABS released the results from its first ever personal fraud survey [4]. A recorded dollar loss of \$AUD980 million was attributable to incidences of personal fraud alone. While personal fraud remained undefined by the ABS, it was dissected into two categories of victimisation; these were 'scams' and 'identity fraud'. A person was recorded as being scammed if they responded to a scam by supplying information and/or money [4]. To become a victim of identity fraud, the victim must have had their personal details used by another person without their consent [4].

A distinction is identified between incidence of identity fraud and incidence of identity theft [2] and it is argued that before identity fraud can transpire, identity theft must first occur [10], this detail was not recorded by the $\mathrm{ABS}$.

It is recorded that 23.5 million people within the UK were the target of a scamming event [11], this, represented $48 \%$ of all UK residents at the time of the mass marketing fraud report and an estimated total dollar loss per year is offered with the amount of $£ 3.5$ billion.

A detailed overview of the state of fraud in Australia describing a clear and present hierarchy of fraudster crimes [6] implies an interconnectedness between fraud and scam events. Prenzler and Hayes [6] suggest that jurisdictional inconsistencies and variations in fraud conceptualisation are responsible for the inadequate view of fraud present in society today. This inadequate view is fuelled by a solesource research base which extends from published and incompatible victim report data collected from 
across the globe. It is recognised that without standardisation of estimation and calculation led by consistent classifications, an understanding of the true impact of fraudster crimes and in particular, cybercrime, cannot be realised.

A Framework for Data Mining [12] discussed such approaches as association analysis, classification, prediction, and cluster analysis. The applied study was a supervised study which began by ranking crimes based on their perceived public harm. Fraud achieved fifth place while cybercrime gained first place in the ranking statistics. Pattern visualisation techniques were recommended as the best approach for analysis of cybercrimes [12].

Routine activities theory (RAT) re-emerged as a promising theoretical perspective during 2005 [13] and was applied to incidents of crime in hopes of understanding crime distributions. In 2008, it was proposed that RAT and lifestyle-exposure theory (LET) could be utilised for cybercrime by assessing computer crime victimisation rates [14]. The conclusion suggested that a hybrid of RAT and LET could be used to identify potential targets of computer crime based on online lifestyle and digital guardianship markers [14].

\section{METHODOLOGY}

Hierarchical clustering analysis presents a method of modelling hierarchies within observed data. It has been suggested that a hierarchy of fraud exists [6] which implies that a hierarchy of scams also exists, this can also be inferred for the realm of cybercrime. These hierarchies can be investigated by applying hierarchical analytical techniques such as hierarchical cluster analyses on purpose driven data. The aim of this research is to investigate the presence of hierarchy within scam-based data and this is achieved through the derivation and analysis of scam static features. Following the pattern recognition phase of analysis, model verification is performed by applying discriminant function analysis to the clustering results.

The proposed method used in the divisively breaks the scams down into their static features and agglomeratively reconstructs scams based upon their identified static components, this allows for the determination of the business processes underlying cybercrimes. This approach takes into account each instance of cyber-crime in its whole form and through a process of deconstruction, static elements - the building blocks foundational to the processes and compilation of each crime are revealed. Once cybercrime cases are deconstructed to a state of static feature elements, cases are agglomeratively clustered based upon similarity of static features and cybercrime genres are revealed. This method has been applied to scam cases sourced from national and international institutions and a summary of the results of the CCF methodology appear below.

Over 250 scam cases sourced from 14 different scam reporting agencies and annual reports (see
Table 1 in Appendix) were individually analysed for static features with each scam's resultant composition of static features recorded in the vector space. Following cluster and discriminant function analysis, similar scam cases were grouped according to similarity of static feature composition and it was determined that 7 scam genres exist, significantly less than the recorded 38 identified by the scam sources. Significant scam identifying features were recognised and these can be used to identify and classify new scams as they emerge.

Scam descriptions offer a rich source of information pertaining to the reporting institution's understanding of individual schemes. From analysing the content of a scam description, a detailed representation of scam processes can be understood. The purpose of the analysis performed here was to identify homogeneous subsets of scam cases. This was achieved through the use of hierarchical clustering analysis and discriminant function analysis. The aim of this research was to formulate clusters of scam cases derived from similarity matching principles based upon the purposely derived static features of scam descriptions. It was hypothesized that a smaller number of scam clusters could be found than the publicly acknowledged 38 which were recorded during the data collection phase.

Furthest neighbour hierarchical clustering using the Jaccard binary coefficient was used to partition similar scams. This method of clustering was selected for use because of its natural tendency to find homogeneous subsets within a data set [15].

The furthest neighbour is a method of complete linkage and a description of this appears below in Figure A. For complete linkage the distance between the furthest pair of cases from separate groups is considered. This approach is an agglomerative approach where data is partitioned according to $\mathrm{Pn}, \mathrm{Pn}-1, \ldots, \mathrm{P} 1$. Where $\mathrm{Pn}$ is a single case or cluster and $\mathrm{P} 1$ contains all cases.

The Jaccard coefficient is a binary distance measure and is calculated by a $/(a+b+c)$, where $a=$ the presence of same features in both cases, $b=$ the presence of features in case 1 and the absence of those same features in case 2 , and $c=$ the absence of features in case 1 and the presence of those same features in case 2 .

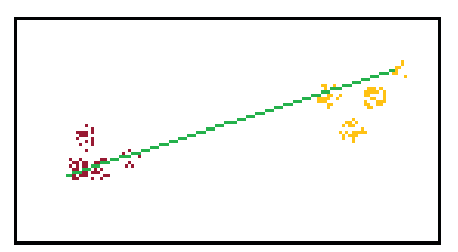

Figure A Complete Linkage

The memberships of scam clusters were recorded and a dendrogram and bar charts tabulating the frequencies within each cluster were created (see Figure 1 and 2 in the Appendix). The result of the hierarchical cluster model was 
evaluated and verified using a discriminant function analysis.

The goal of the discriminant function analysis was to assess the reliability of the model where a reliable model was defined as a model in which the (n-1) discriminant functions combined account for at least $95 \%$ of variability within the data. A model which accounted for at least $95 \%$ of variability could then be claimed to be at least 95\% accurate. Another goal of the discriminant function analysis was to identify which scam static features were significant to cluster membership prediction.

\section{RESULTS}

The cluster solution which was accurate at least $95 \%$ of the time and contained the fewest number of clusters would satisfy the constraints of the investigation. Using the furthest neighbour Jaccard coefficient hierarchical cluster model and removing all insignificant static features, the $250+$ scam cases from 38 scam categories could be clustered into only 7 clusters of scam types - called scam genres, whilst achieving 95\% accuracy. Of the 82 scam static features derived, 68 were found to be significant to the variation in the model and thus impacted the placement of scam cases into scam clusters (see Table 3, 4, and 5 in the Appendix).

The validation of the furthest neighbour, Jaccard coefficient hierarchical clustering model for scambased research carries implications for the usability of text-based publicly accessible data in mixed methodological analysis. These results also confirm the variability of scam descriptions across jurisdictions and provide evidence for the necessity for the standardisation of terminology.

These results confirm that the fewest number of clusters with the least number of scam memberships, inferring homogeneity across clusters and among cases is 7, and scam cases can be accurately allocated to a scam genre (cluster) $95 \%$ of the time using the furthest neighbour, Jaccard coefficient hierarchical clustering model.

Over two hundred and fifty individual scam cases and 82 purposely derived scam static features belonging to 38 separate source classified scam genre categories were analysed using an unsupervised agglomerative furthest neighbour, Jaccard coefficient hierarchical clustering model which was verified and tested for reliability by a discriminant function analysis.

This method achieved 95\% accuracy in partitioning scam cases into scam genres. The 38 source classified scam genres were reduced down to only 7 scam genres which were Financial Gain through Low Level Trickery, Financial Gain and Information Gathering through Developed Story Based Applications, Participation and Information Gathering through Employment Based Strategies, Financial Gain through Implied Necessary Obligation, Information Gathering through Legitimate Looking Appeals, Financial Gain through Merchant and Customer Based Exploitation, and Financial Gain and Information Gathering through Marketing Opportunities.

It was discovered that only 68 of the 82 scam static features were required to achieve a $95 \%$ level of accuracy in scam membership and the most prominent of these static features were what the scam offered, the role of the victim, the goal of the scammer, and the method of scam introduction.

It is demonstrated that scams are currently over classified within current literature and that only 7 scam types or scam genres exist compared to the 38 recorded source-classified scam categories.

\section{DISCUSSION}

\section{Financial Gain through Low Level Trickery}

The first scam genre contains 72 scam cases which are detailed in the appendix. This scam genre is made up of scam cases that involve the most basic forms of trickery. These involve scams that are not necessarily thorough in planning and detail. Victims falling for scam genre one scams would take people and communications at face value and not expend time or energy on investigating scam claims or the people behind them. These scams target the individual or company for once off transactions initially and where possible, if there were potential for the scam to be extended to elicit more funds from the victim, this may be pursued.

Scam genre 1 contains scams are at the most basic level after the victim's cash or ability to get loans. Door to door scams often involve the soliciting of services that are paid for and never performed. Psychic and clairvoyant scams involve the soliciting of services or merchandise that is paid for and is not what it had promised to be. Cheque overpayment scams involve the overpayment for a purchase and a request for the balance to be wired back to the sender. In this situation, the cheque is fraudulent and the scammer walks away with the victim's money after they have refunded the difference and financial advice scams involve soliciting supposed financial advice for an upfront fee. Whether or not the advice is useful is irrelevant since the victim has just paid a scammer and the scammer has walked away with the victim's money and possibly their personal and private details to use in a future identity based scam. Similarity among scams found in scam genre 1 emerge, the most obvious is the payment of funds to the scammer.

\section{Financial Gain and Information Gathering through Developed Story Based Applications}

The second scam genre contains 74 scam cases. This scam genre is made up of scam cases that involve complex planning and detail. These scams hinge on the opportunistic nature of the general 
public as well as the scammer. In this sense a common bond is formed between the scammer and their victims and that is opportunity. The first scam in scam genre 2 is the charity scam. This scam relies on the poverty and necessity of others, this scam also emerges during natural or manmade disaster. These scams rely on assumed public knowledge of a cohort of individuals or a global tragedy. They are story based scams and offer to their victims the opportunity to make a difference in the world through financial assistance.

The ultimate goal of the scams found in scam genre 2 is money, the same as scam genre 1 however, the method of realising this goal is different. The grouping of unexpected prizes and chain letters together with charity scams and Nigerian 419 scams suggests some similarity in scam perpetrations; further investigation might prove useful in determining on what grounds these scams are alike. This may be due to the story based nature of all of these scams. Another goal which manifests in dating and romance scams, Nigerian 419 scams, and even spam offers is the collection of personal or private information.

\section{Participation and Information Gathering through Employment Based Strategies}

The third scam genre contains 22 scam cases. This scam genre is made up of scam cases that involve complex planning and detail, similar to that found in scam genre 2 however, the scams in scam genre 3 target the individual in the sense that they seek participation from victims. Each scam listed in scam genre three involves a level of victim 'employment' in which the victim participates in the scheme; normally a laundering scam, and for their participation they are financially rewarded. These scams can often lead to identity theft and other identity based crimes since in becoming involved in one of these scams the victim may have been an applicant for what they had believed was an authentic employment opportunity. With their application, the victim would have supplied the scammer/s with a full working and educational history, full name and date of birth as well as bank account details.

\section{Financial Gain through Implied Necessary Obligation}

The fourth scam genre contains 17 scam cases. This scam genre is made up of scam cases that require victim call backs or responses for the scam to be successful. The scams found here are different to those seen in scam genre one, two, and three. Most of these scams rely on alternative technologies to that of the Internet and World Wide Web for dissemination. There are a mixture of scams here that aim to trick the victim into a response and thus facing un-expected and unrealised charges. Regardless of the method of the scam, or the role of the victim, this scam genre contains scams that aim to make money from the victim in ways that would seem necessary or pertinent to the situation.

\section{Information Gathering through Apparently Authentic Appeals}

The fifth scam genre contains 38 scam cases. This scam genre is made up of scam cases that involve high level knowledge of how systems operate and contains those scams that are syntactically driven such as spyware and key logger scams. This scam genre also contains scams that seek information for the purpose of identity related crimes such as identity theft and credit/debit card fraud. The reason why syntactic scams using spyware and key loggers are clustered along with identity theft and credit/debit card scams is because syntactic attacks are dispersed with the goal of gathering victim identity credentials or other forms of information. Therefore, spyware and key logging scams are identified as a tool for the success of information gathering scams such as identity theft and credit/debit card scams. Also found in scam genre 5 are phishing scams which are also synonymous with identity theft and credit/debit card fraud.

\section{Financial Gain through Merchant and Customer Based Exploitation}

The sixth scam genre contains 24 scam cases. This scam genre is made up of scam cases that incorporate the roles of both the seller and buyer in the scam description. These scams are all transaction based scams involving a buyer and a seller; shill bidding, bid shielding, merchandise non-delivery, payment non-delivery, and product authenticity. The goal of this group of scams is financial gain which is achieved through various versions and applications of similarly styled scams. These scams are well researched and developed even though the victim and scammer only communicate for a short period of time.

\section{Financial Gain and Information Gathering through Marketing Opportunities}

The final scam genre is scam genre 7 which contains 30 scam cases. This scam genre is made up of scam cases that involve the exploitation of investment opportunities and contains a mixture of scam types including Ponzi and pyramid, identity theft, computer prediction software, investment seminars, charity fraud, affinity fraud, get rich quick scams and 419 advance fee fraud. Without further detailed analysis of the inter-connected nature of the suite of compiled static features fitting into this category, the presence of this mixture of scam titles is interpreted as hinging on the suggestion of investment opportunities within each scam case. The scams within scam genre 7 are marketed as money making opportunities, whether through investment, business opportunity, shares or gambling. However, the goal of the scammer is financial gain and in some instances this extends to information gathering. 


\section{The Top Four Scammer Business Processes}

The top four cybercriminal business processes were identified and these account for the majority of the variation in scam genre placement which means that a scam's type can be identified early on in the scamming process by these 4 static features. By acknowledging these static features, the type of scam a scheme is can be confidently identified and future paths of communication and transaction flow can then be projected leading the way to the positive mapping of scam case progress and the identification of optimum paths of interception by law enforcement.

While it would be over confident to suggest that intercepting scam communications and transactions will lead to scammer prosecution, by identifying and projecting the business processes involved in scamming communications and transactions, optimum paths of interception causing the greatest damage to the scammer exhausting their time and funds can be realised.

The four most significant static features crucial to the successful scam campaign and therefore, the most important business processes that scammers build their schemes upon are: a) what the scam offers, b) the role of the victim, c) the goal of the scammer, and d) method of scam introduction.

If a cybercriminal were to begin planning a new scam campaign, these are the priority features that would need to be known and addressed by the scammer during the business development phase. Before launching a campaign, the scammer must know what he/she seeks, they must have an end goal decided, knowing this, the scammer develops a scam campaign which will deliver the desired outcome.

From knowledge of the desired outcome, the scammer must then decide on how he/she will introduce the scam to the target, further to this, contingencies would be made on how to reach as many targets as necessary to meet and exceed the intended goal. The scammer must know how to get the target involved in the scam, to do this, the scam must offer something of value to the target and finally, before the campaign can be finalised, the scammer must know what role he/she would play in the campaign, and therefore, what role the target will play.

By identifying these four key elements of the cybercriminal's business process, scams can be confidently identified and acted upon by the relevant authorities early on in the scamming campaign. Most importantly and in most cases, these key features can be identified from the very first scam communication, which means that the CCF methodology can be used as a tool for identifying possible scam communications before an incident of scamming even occurs. This can be demonstrated with the following example:

"Dear Beloved Friend, I am Mrs Lovelin Vincent, I was married to Late Chief Vincent Williams a government contractor I have the sum of
US\$5.5m which I inherited from my late husband before he was killed by unknown people on his way returning from a business trip. I want this money to be transfer in an account in your country for charity, widow's and church in your area. God bless you and your family Yours in the Lord."

The above is an example of what is usually termed a 419 scam. In this example, the scammer is pretending to be the widow of an influential man who was tragically killed and who now has a substantial sum of money that she wishes to donate to those charities within the intended victim's vicinity. This is the first communication of this 419 scam and the business processes used by the scammer can be identified as: a) what the scam offers - money, a chance to offer assistance, b) the role of the victim - randomly chosen and if the scam were to eventuate, the victim would assume the role of a third party or 'courier' to transfer and disseminate the supposed funds, c) the goal of the scammer - to gain access to the victim's bank account details and take their money, and d) method of scam introduction - email communication.

\section{CONCLUSION}

The cybercrime classification framework (CCF) can be expanded to incorporate all current and future forms of cybercrime. The ease with which the framework can be updated will assist authorities, industry and business in remaining constantly prepared with the most up to date and relevant information available on the instances of and types of cybercrimes circulating the Internet and targeting corporate operations and individuals.

Due to the user friendly nature of the CCF, it can easily be adopted by small to large businesses and the industrial sector to consistently and effectively manage and communicate their experiences of cybercrime to the authorities. Individual agencies can map their existing known schemes into the CCF and the authorities can use the $\mathrm{CCF}$ to develop consistent terms for further defining within the prosecution process as well as use the $\mathrm{CCF}$ to enhance transnational cooperation and coordination.

The adoption of the cybercrime classification framework for state and federal reporting institutions would also encourage collaboration and useful interpretation of scam and cybercrime based statistics to give meaningful, accurate and up to date evaluations of cyber-based incidents and finally, the CCF methodology described here would improve the efficiency in identifying, tracking and monitoring cybercrimes.

\section{APPENDIX}


Table 1: Scam source and its frequency contribution to the sample

\begin{tabular}{|lc|}
\hline \multicolumn{1}{|c}{ Source } & Frequency \\
\hline \hline Scamwatch & 40 \\
Australian Competition and Consumer Commission & 35 \\
United States Postal Inspectors Service & 33 \\
Looks too good to be true & 28 \\
Scam smart & 28 \\
United Kingdom Office of Fair Trading & 27 \\
Internet Crime Complaint Center & 10 \\
Federal Bureau of Investigation & 13 \\
Environics Research Group & 12 \\
FIDO & 12 \\
On guard online & 10 \\
Australian Bureau of Statistics & 8 \\
US-Cert & 7 \\
Queensland Police Service & 5 \\
\hline
\end{tabular}

Table 2: List of derived scam static features

\begin{tabular}{|c|c|c|c|}
\hline Features & Type & Features & Type \\
\hline Seller & Role of the victim & \begin{tabular}{|l|} 
Love affection and \\
connection
\end{tabular} & $\begin{array}{l}\text { What the } \\
\text { claimed }\end{array}$ \\
\hline Customer & Role of the victim & Government agency & $\begin{array}{l}\text { What the scheme } \\
\text { claimed }\end{array}$ \\
\hline Target Spercific & Role of the victim & Large return & What the scheme \\
\hline Unassociated & Role of the victim & Effective & $\begin{array}{l}\text { What the scheme } \\
\text { claimedd }\end{array}$ \\
\hline Received & Method of introduction & Refund available & $\begin{array}{l}\text { What the scheme } \\
\text { claimed }\end{array}$ \\
\hline Introduced & Method of introduction & Fraudulent activity & $\begin{array}{l}\text { What the scheme } \\
\text { claimed }\end{array}$ \\
\hline Sought & Method of introduction & Na credit check required & What the scheme \\
\hline Website & $\begin{array}{l}\text { Taul for scheme } \\
\text { profiferation }\end{array}$ & Quick respanse & $\begin{array}{l}\text { What the scheme } \\
\text { required from the wictim }\end{array}$ \\
\hline Face to face & $\begin{array}{l}\text { Taol for scheme } \\
\text { profiferation }\end{array}$ & Confidentiality & $\begin{array}{l}\text { What the scheme } \\
\text { required from the victim }\end{array}$ \\
\hline Text message & $\begin{array}{l}\text { Taol for sccheme } \\
\text { profiferatiton }\end{array}$ & $\begin{array}{l}\text { Payment of upfront } \\
\text { costs }\end{array}$ & $\begin{array}{l}\text { What the scheme } \\
\text { re cuired from the viction }\end{array}$ \\
\hline Phane call & $\begin{array}{l}\text { Taol far scheme } \\
\text { profiferation }\end{array}$ & Receive and send funds & What the scheme \\
\hline Seminar & $\begin{array}{l}\text { Tarl for scheme } \\
\text { profiferation }\end{array}$ & Call a premium number & $\begin{array}{l}\text { What the scheme } \\
\text { required from the victim }\end{array}$ \\
\hline Internet forum & Tool far scheme & Transfer excess & What the scheme \\
\hline Internet pop up & Tool far scheme & Complete sale outside & $\begin{array}{l}\text { terequired from the wi } \\
\text { What the scheme }\end{array}$ \\
\hline Email & $\begin{array}{l}\text { profliferation } \\
\text { Tool far scheme }\end{array}$ & auction & required from the victim \\
\hline Demat & $\begin{array}{l}\text { proliferation } \\
\text { Tonl for som }\end{array}$ & S Send onto athers & required from the : \\
\hline & proliferation & Recruit others & required from the victim \\
\hline Advertisement & $\begin{array}{l}\text { Taol far scheme } \\
\text { profiferatition }\end{array}$ & $\begin{array}{l}\text { Supply parsanal } \\
\text { infirmation }\end{array}$ & $\begin{array}{l}\text { What the scheme } \\
\text { required frigm the victim }\end{array}$ \\
\hline Fax & $\begin{array}{l}\text { Toul far screme } \\
\text { profiferation }\end{array}$ & $\begin{array}{l}\text { Supply bank account } \\
\text { information }\end{array}$ & $\begin{array}{l}\text { what the scheme } \\
\text { required from the victim }\end{array}$ \\
\hline Prize ar money & $\begin{array}{l}\text { What the scheme } \\
\text { offered }\end{array}$ & Investment & What the scheme \\
\hline Human interaction & What the scheme & Make a donation & What the scheme \\
\hline Financial return & \begin{tabular}{|l|} 
What the scheme \\
offered
\end{tabular} & Use alternative shipment & $\begin{array}{l}\text { What the scheme } \\
\text { required from the victim }\end{array}$ \\
\hline Membership & $\begin{array}{l}\text { What the scheme } \\
\text { offered }\end{array}$ & Syntactic & Method of the scheme \\
\hline Advice or assistance & $\begin{array}{l}\text { What the scheme } \\
\text { offorod }\end{array}$ & Semantic & Method of the scheme \\
\hline Overpayment & $\begin{array}{l}\text { What the scheme } \\
\text { offered }\end{array}$ & $\begin{array}{l}\text { Campromised website or } \\
\text { phon whets site }\end{array}$ & Scammers toolbo $x$ \\
\hline Treatment & $\begin{array}{l}\text { What the scheme } \\
\text { offered }\end{array}$ & Disguised as invoice & Scammers toolbox \\
\hline Employment & $\begin{array}{l}\text { What the scheme } \\
\text { offered }\end{array}$ & IInferiar merchandise & Scammers tooltox $x$ \\
\hline $\begin{array}{l}\text { Opportunity for self or } \\
\text { others }\end{array}$ & $\begin{array}{l}\text { What the scheme } \\
\text { offered }\end{array}$ & Use of flasified forms & Scammers toolbox \\
\hline Holiday & $\begin{array}{l}\text { What the scheme } \\
\text { offered }\end{array}$ & Use of paraphernalia & Scammers toolbox \\
\hline Financial services & $\begin{array}{l}\text { What the scheme } \\
\text { offered }\end{array}$ & Goods never sent & Scammers toolbo $x$ \\
\hline Gaod luck & $\begin{array}{l}\text { What the scheme } \\
\text { offered }\end{array}$ & Story based & Scammers toolto $x$ \\
\hline Property & $\begin{array}{l}\text { What the scheme } \\
\text { offered }\end{array}$ & Verifiable street address & Scammers toolbo $x$ \\
\hline Share tips & \begin{tabular}{|l} 
What the scheme \\
offered
\end{tabular} & Looks genuine & Scammers toolbo $x$ \\
\hline Services & $\begin{array}{l}\text { What the scheme } \\
\text { offered }\end{array}$ & \begin{tabular}{|l} 
Exploitation of legitimate \\
business
\end{tabular} & Scammers toolbo $x$ \\
\hline Merchandise & $\begin{array}{l}\text { What the scheme } \\
\text { offered }\end{array}$ & Testimanials & Scammers toolbox \\
\hline Partial payment & $\begin{array}{l}\text { What the scheme } \\
\text { offered }\end{array}$ & $\begin{array}{l}\text { Reward greater than } \\
\text { upfrant cost }\end{array}$ & Scammers toolbox \\
\hline Insight & $\begin{array}{l}\text { What the scheme } \\
\text { claimed }\end{array}$ & $\begin{array}{l}\text { Futher contact by email } \\
\text { or phone }\end{array}$ & Scammers toolbo $x$ \\
\hline Legal & What the scheme & Polite broken English & Scammers toolbox \\
\hline From financial & What the scheme & Financial gain & Goal of the scheme \\
\hline Information update & What the scheme & Information gathering & Goal of the scheme \\
\hline Government approw & $\begin{array}{l}\text { What the scheme } \\
\text { claimed }\end{array}$ & Participation & Goal of the scheme \\
\hline
\end{tabular}

Table 3: DFA equality of group means

\begin{tabular}{|c|c|c|c|c|c|}
\hline & \begin{tabular}{c|c|}
$\begin{array}{c}\text { Wilks' } \\
\text { Lambda }\end{array}$ \\
\end{tabular} & $\mathrm{F}$ & df1 & $\mathrm{df} 2$ & Sig. \\
\hline Seller & .904 & 4.758 & 6 & 270 & .000 \\
\hline Customer & 268 & 123.176 & 6 & 270 & .000 \\
\hline TargetSpecific & .946 & 2.552 & 6 & 270 & .020 \\
\hline Unassociated & .411 & 64.366 & 6 & 270 & .000 \\
\hline Received & .559 & 35.474 & 6 & 270 & .000 \\
\hline Introduced & .786 & 12.242 & 6 & 270 & .000 \\
\hline Sought & .667 & 22.466 & 6 & 270 & .000 \\
\hline WebsiteorOnlineAuction & .824 & 9.589 & 6 & 270 & .000 \\
\hline Face2Face & .853 & 7.736 & 6 & 270 & .000 \\
\hline Text & .820 & 9.885 & 6 & 270 & .000 \\
\hline Phone & .935 & 3.124 & 6 & 270 & .006 \\
\hline Seminar & .910 & 4.465 & 6 & 270 & .000 \\
\hline InternetForum & .837 & 8.753 & 6 & 270 & .000 \\
\hline InternetPopUp & .791 & 11.908 & 6 & 270 & .000 \\
\hline Email & .773 & 13.185 & 6 & 270 & .000 \\
\hline Post & .807 & 10.787 & 6 & 270 & .000 \\
\hline Advertisement & .753 & 14.752 & 6 & 270 & .000 \\
\hline Fax & .955 & 2.142 & 6 & 270 & .049 \\
\hline PrizeorMoney & .638 & 25.566 & 6 & 270 & .000 \\
\hline Humaninteraction & .966 & 1.601 & 6 & 270 & .147 \\
\hline FinancialReturn & .626 & 26.842 & 6 & 270 & .000 \\
\hline Membership & .860 & 7.307 & 6 & 270 & .000 \\
\hline AdviceorAssistance & .908 & 4.584 & 6 & 270 & .000 \\
\hline Overpayment & .904 & 4.758 & 6 & 270 & .000 \\
\hline Treatment & .895 & 5.300 & 6 & 270 & .000 \\
\hline Employment & .156 & 243.588 & 6 & 270 & .000 \\
\hline OpportunityForSelforothers & .793 & 11.764 & 6 & 270 & .000 \\
\hline Holiday & .932 & 3.259 & 6 & 270 & .004 \\
\hline FinancialServices & .946 & 2.550 & 6 & 270 & .020 \\
\hline GoodLuck & .973 & 1.234 & 6 & 270 & 289 \\
\hline Property & .942 & 2.747 & 6 & 270 & .013 \\
\hline Senvices & .927 & 3.536 & 6 & 270 & .002 \\
\hline Merchandise & .672 & 21.982 & 6 & 270 & .000 \\
\hline PartialPayment & .923 & 3.736 & 6 & 270 & .001 \\
\hline Insight & .958 & 1.959 & 6 & 270 & .072 \\
\hline Legal & .932 & 3.301 & 6 & 270 & .004 \\
\hline Fromfinanciallnstitution & .874 & 6.511 & 6 & 270 & .000 \\
\hline DetailUpdateorConfirmationRequired & .709 & 18.475 & 6 & 270 & .000 \\
\hline GovernmentApproved & .951 & 2.332 & 6 & 270 & .033 \\
\hline LoveAffectionConnection & .959 & 1.928 & 6 & 270 & .076 \\
\hline Governmentagency & .981 & .883 & 6 & 210 & .508 \\
\hline LargeReturn & .617 & 27.938 & 6 & 270 & .000 \\
\hline Effective & .886 & 5.807 & 6 & 270 & .000 \\
\hline RefundAvailable & .988 & .557 & 6 & 270 & .764 \\
\hline Fraudulentactivity & .882 & 6.009 & 6 & 270 & .000 \\
\hline ShareTips & .932 & 3.258 & 6 & 270 & .004 \\
\hline NoCreditcheckRequired & .986 & .649 & 6 & 270 & 691 \\
\hline LitlleorNoRisk & .878 & 6.253 & 6 & 270 & .000 \\
\hline From Corporate OrGovofficial & .956 & 2.048 & 6 & 270 & .060 \\
\hline QuickResponse & .949 & 2.426 & 6 & 270 & .027 \\
\hline Confidentiality & .910 & 4.436 & 6 & 270 & .000 \\
\hline PayupFrontCosts & .758 & 14.388 & 6 & 270 & .000 \\
\hline ReceiveAndSendFunds & .778 & 12.822 & 6 & 270 & .000 \\
\hline CallaPremiumNumber & .740 & 15.795 & 6 & 270 & .000 \\
\hline TransferExcess & .916 & 4.125 & 6 & 270 & .001 \\
\hline CompleteSaleoutsideofAuction & .923 & 3.736 & 6 & 270 & .001 \\
\hline SendOntoothers & .960 & 1.870 & 6 & 270 & .086 \\
\hline Recruitothers & .735 & 16.187 & 6 & 270 & .000 \\
\hline SupplyPersonallinformation & .764 & 13.921 & 6 & 270 & .000 \\
\hline SupplyBankAccDetails & 797 & 11.468 & 6 & 270 & .000 \\
\hline Invest & .688 & 20.437 & 6 & 270 & .000 \\
\hline MakeADonation & .912 & 4.336 & 6 & 270 & .000 \\
\hline AlternativeShipment & .767 & 13.700 & 6 & 270 & .000 \\
\hline Syntactic & .659 & 23.246 & 6 & 270 & .000 \\
\hline Semantic & .680 & 21.219 & 6 & 270 & .000 \\
\hline CompromisedWebsiteorfalseWebsite & .791 & 11.905 & 6 & 270 & .000 \\
\hline Disguisedasinvoice & .965 & 1.650 & 6 & 270 & 134 \\
\hline InferiorMerchandise & .919 & 3.975 & 6 & 270 & .001 \\
\hline UseoffalsifiedForms & .853 & 7.777 & 6 & 270 & .000 \\
\hline UseofParaphernalia & .854 & 7.708 & 6 & 270 & .000 \\
\hline Goods NeverSent & .804 & 10.967 & 6 & 270 & .000 \\
\hline StoryBased & .809 & 10.598 & 6 & 270 & .000 \\
\hline VerifiableStreetAddress & .990 & .469 & 6 & 270 & .831 \\
\hline LooksGenuine & .880 & 6.125 & 6 & 270 & .000 \\
\hline ExploitLegitBusiness & .924 & 3.727 & 6 & 270 & .001 \\
\hline Testimonials & .921 & 3.870 & 6 & 270 & .001 \\
\hline RewardGreaterThanUpfrontcosts & .945 & 2.631 & 6 & 270 & .017 \\
\hline FurtherContactbyEmailorPhone & .974 & 1.218 & 6 & 270 & 297 \\
\hline PoliteBrokenEnglish & .984 & .732 & 6 & 270 & 624 \\
\hline FinancialGain & .326 & 92.958 & 6 & 270 & .000 \\
\hline Information & .498 & 45.412 & 6 & 270 & .000 \\
\hline Participation & .653 & 23.893 & 6 & 270 & .000 \\
\hline
\end{tabular}




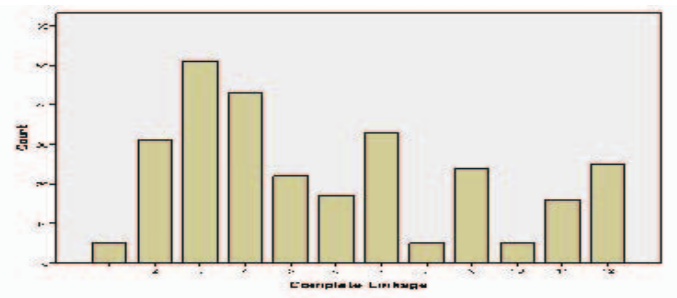

A) 12 Cluster Solution - Cluster Membership Frequency

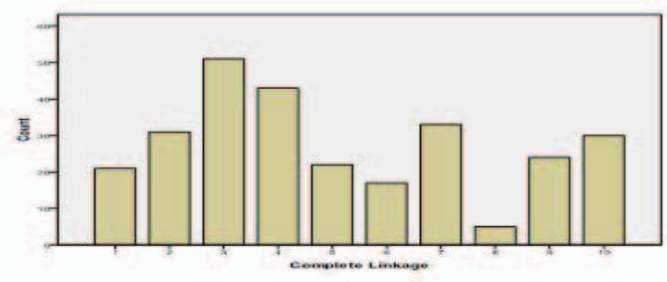

C) 10 Cluster Solution - Cluster Membership Frequency

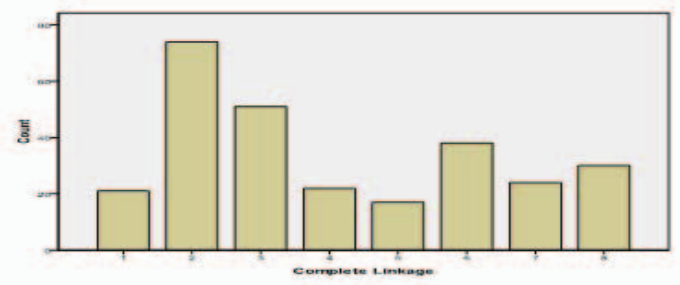

E) 8 Cluster Solution - Cluster Membership Frequency

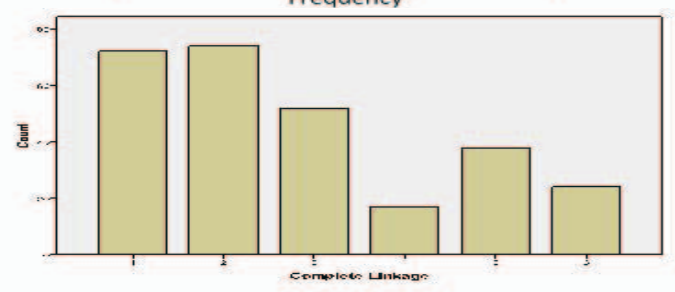

G) 6 Cluster Solution - Cluster Membership Frequency

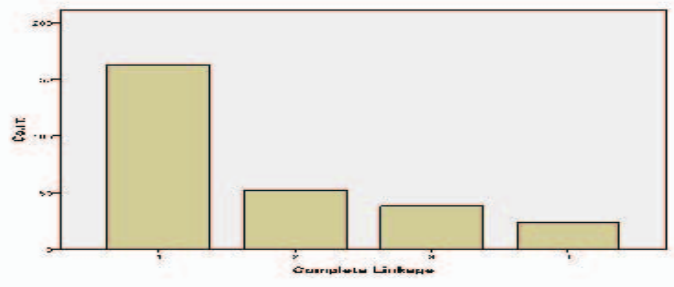

1) 4 Cluster Solution - Cluster Membership Frequency

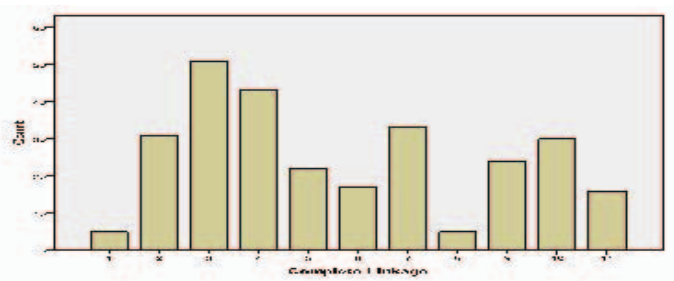

B) 11 Cluster Solution - Cluster Membership Frequency

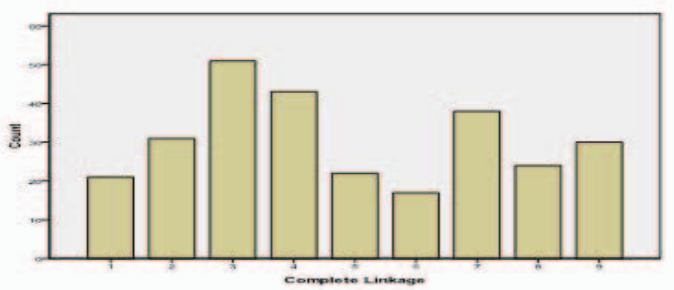

D) 9 Cluster Solution - Cluster Membership Frequency

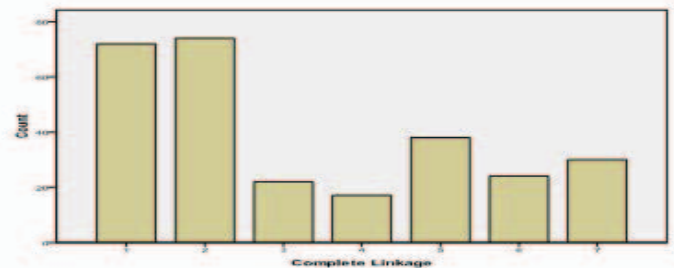

F) 7 Cluster Solution - Cluster Membership Frequency

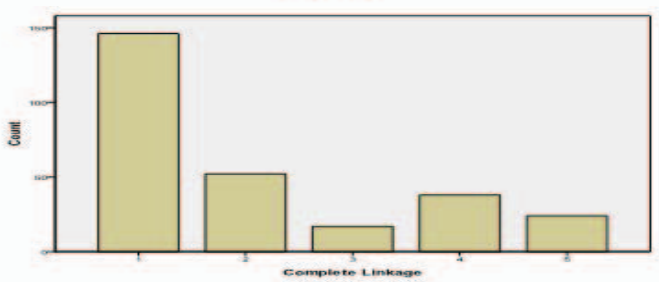

H) 5 Cluster Solution - Cluster Membership Frequency

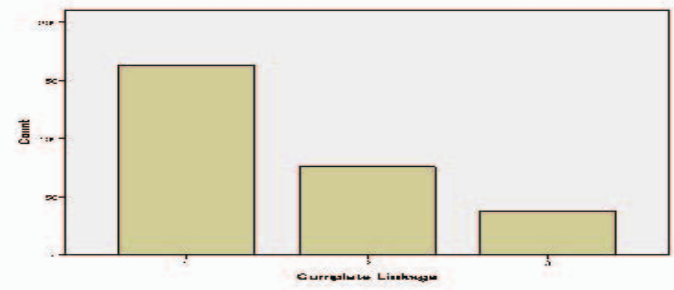

1) 3 Cluster Solution - Cluster Membership Frequency

Figure 1: Frequency bar charts of scam cluster memberships 
Table 4: DFA Eigenvalues

\begin{tabular}{|l|r|r|r|r|}
\hline Eunction & Eigenvalue & $\begin{array}{c}\% \text { of } \\
\text { Variance }\end{array}$ & Cumulative \% & $\begin{array}{c}\text { Canonical } \\
\text { Correlation }\end{array}$ \\
\hline 1 & $10.838^{\mathrm{a}}$ & 31.6 & 31.6 & .957 \\
2 & $9.662^{\mathrm{a}}$ & 28.2 & 59.8 & .952 \\
3 & $6.284^{\mathrm{a}}$ & 18.3 & 78.2 & .929 \\
4 & $3.677^{\mathrm{a}}$ & 10.7 & 88.9 & .887 \\
5 & $1.997^{\mathrm{a}}$ & 5.8 & 94.7 & .816 \\
6 & $1.805^{\mathrm{a}}$ & 5.3 & 100.0 & .802 \\
\hline
\end{tabular}

Table 5: DFA Tests of significance

\begin{tabular}{|l|}
\begin{tabular}{|l|r|r|r|r|}
\hline $\begin{array}{l}\text { Wilks } \\
\text { Test of } \\
\text { Function(s) }\end{array}$ & $\begin{array}{c}\text { Wilks } \\
\text { Lambda }\end{array}$ & $\begin{array}{c}\text { Chi- } \\
\text { square }\end{array}$ & df & \multicolumn{1}{c|}{ Sig. } \\
\hline 1 through 6 & .000 & 2434.828 & 486 & .000 \\
2 through 6 & .000 & 1861.482 & 400 & .000 \\
3 through 6 & .003 & 1312.420 & 316 & .000 \\
4 through 6 & .025 & 851.730 & 234 & .000 \\
5 through 6 & .119 & 493.856 & 154 & .000 \\
6 & .357 & 239.246 & 76 & .000 \\
\hline
\end{tabular}
\end{tabular}

Table 6: Scam genre 1

\begin{tabular}{|c|c|c|c|c|c|}
\hline Scam Name & Source & Country & Scam Nlame & Source & Country \\
\hline Door to door & SW & Aus & Cold calling & ACCC & Aus \\
\hline Psychic \& clairvoyant & SW & Aus & Share promotions \& hot tips & ACCC & Aus \\
\hline Office supply & SW & Aus & Gambling software & ACCC & Aus \\
\hline Drectories \& advertising & SW & Aus & Overpayment & ACCC & Aus \\
\hline Fake online pharmacies & SW & Aus & Wiracle cures & ACCC & Aus \\
\hline Weight loss & SW & Aus & Weight loss & ACCC & Aus \\
\hline Wiracle cures & SW & Aus & Fake online pharmacies & ACCC & Aus \\
\hline Domain name renewal & SW & Aus & Psychic \& clairvoyant & ACCC & Aus \\
\hline Cheque overpayment & SW & Aus & Door to door & ACCC & Aus \\
\hline Cold calling & SW & Aus & Business oppotunnities & ACCC & Aus \\
\hline Counterfet cashiers check & 103 & USA & Smal business & ACCC & Aus \\
\hline Internet extortion & 103 & USA & Direct entry unauthorised advertising & ACCC & Aus \\
\hline Financial advice & ABS & Aus & Wystery shopper & USPIS & USA \\
\hline Pyramid schemes & ABS & Aus & Credit card fraud & USPIS & USA \\
\hline Credt \& bank card & ABS & AUS & Chid support collection scheme & USPIS & USA \\
\hline Fake clainoyant & OFT & UK & Social security schemes & USPIS & USA \\
\hline Bogus investment & OFT & UK & Unclaimed income tax refund & USPIS & USA \\
\hline Wiracle heath cure & OFT & UK & Unclaimed funds & USPIS & USA \\
\hline Bogus heath product & ERG & Can & Property tax exemption & USPIS & USA \\
\hline Investment fraud & ERG & Can & Cut rate heath insurance & USPIS & USA \\
\hline Advance fee vacation fraud & ERG & Can & hvestment fraud & USPPS & USA \\
\hline Overpayment for sale of merchandise & ERG & Can & Solictitions disguised as invoices & USPIS & USA \\
\hline Wiracle heath \& s simming & OFT & UK & Oi \& gas investment & USPIS & USA \\
\hline Clainoyant \& psychic maliling & OFT & UK & Land fraud & USPIS & USA \\
\hline High risk investment & OFT & UK & legal sweepstakes & USPIS & USA \\
\hline Roling labs & $\mathrm{FBI}$ & USA & Government look alike mail & USPIS & USA \\
\hline Letter of credit fraud & FBI & USA & Free vacation scams & USPIS & USA \\
\hline Prime bank note & $\mathrm{FB|}$ & USA & Receipt for unsolicted merchandise & USPPS & USA \\
\hline Weight loss claims & 060 & USA & Missing persons & USPIS & USA \\
\hline Cure al products & 060 & USA & Fraudulent heath \& medical products & USPIS & USA \\
\hline Check overpayment & 060 & USA & Astrology psychic \& clairvoyant & sS & Aus \\
\hline Pharmacy fraud & L2G2BT & USA & Cheque overpayment & ss & Aus \\
\hline Investments fraud & L2G2BT & USA & Share trading & SS & Aus \\
\hline Wutiple bidding & L2G2BT & USA & Cold calling & FIDO & Aus \\
\hline Counterfeit cashiers check & L2G2BT & USA & Fake debt invoices & FIDO & Aus \\
\hline Heath \& diet scams & USC & USA & Fraudulent cheques \& credit cards & QPOL & Aus \\
\hline
\end{tabular}


Table 7: Scam genre 2

\begin{tabular}{|c|c|c|c|c|c|}
\hline Scam Nlame & Source & Country & Scam Name & Source & Country \\
\hline Charity & SW & Aus & Advance fee scam & L2G2BT & USA \\
\hline Dating \& romance & SW & Aus & Chartilies fraud & L2G2BT & USA \\
\hline Fax back & SW & Aus & Nigerian 419 & L2G2BT & USA \\
\hline Spam offers & SW & Aus & Foreign lottery & L2G2BT & USA \\
\hline Upfront payment & SW & Aus & Sweepstakes \& prizes & L2G2BT & USA \\
\hline Nigerian 419 & SW & Aus & Lottery & $A C C C$ & Aus \\
\hline Lottery \& sweepstakes & SW & Aus & Fake prize & $A C C C$ & Aus \\
\hline Unexpected prizes & SW & Aus & Chain letters & $A C C C$ & Aus \\
\hline Chain letters & SW & Aus & Nigerian scam & $A C C C$ & Aus \\
\hline Lotteries & 103 & USA & Inheritance scam & $A C C C$ & Aus \\
\hline Nigerian letter 419 & 103 & USA & Dating \& romance & $A C C C$ & Aus \\
\hline Advance fee fraud & ABS & Aus & Distributorship \& franchise fraud & USPS & USA \\
\hline Chain letters & ABS & Aus & 900 telephone numbers & USPIS & USA \\
\hline Lottery & ABS & Aus & Advance fee loan schemes & USPSS & USA \\
\hline Advance fee & OFT & UK & Charity fraud & USPIS & USA \\
\hline International sweepstakes & OFT & UK & Chain letters & USPIS & USA \\
\hline Prize draw pitch & OFT & UK & Free prize schemes & USPIS & USA \\
\hline Bogus lottery & OFT & UK & Foreign lotteries & USPSS & USA \\
\hline High pressure sales pitch vacation & ERG & Can & Telemarketing fraud & USPIS & USA \\
\hline Prize lottery \& sweepstakes & ERG & Can & Home improvement \& repair & USPIS & USA \\
\hline West African 419 & ERG & Can & Phony inheritance & USPIS & USA \\
\hline Advance fee loan & ERG & Can & Prison pen pal money order scam & USPIS & USA \\
\hline Upiront fee for credt card & ERG & Can & Nigerian & ss & Aus \\
\hline Prize draw \& sweepstakes & OFT & UK & Lottery prizes & sS & Aus \\
\hline Foreign lottery & OFT & UK & Holiday prizes & sS & Aus \\
\hline Premium rate telephone prize & OFT & UK & Internet bride & ss & Aus \\
\hline African advance fee frauds foreign money ma & OFT & UK & Inheritance scam & ss & Aus \\
\hline Bogus holiday club & OFT & UK & Churches & ss & Aus \\
\hline Telemarketing & $\mathrm{FB|}$ & USA & Bowling clubs & sS & Aus \\
\hline Nigerian or 419 & $F B \mid$ & USA & Hit man & sS & Aus \\
\hline Advance fee scheme & FBI & USA & Dating dowry \& romance & sS & Aus \\
\hline Nigerian email & 060 & USA & Donation & SS & Aus \\
\hline Foreign lotteries & OGO & USA & Nigerian letter \& advance fee fraud & FIDO & Aus \\
\hline Pay in advance credt offers & 060 & USA & Lottery scams & FIDO & Aus \\
\hline Debt relief & 060 & USA & Request to use bank account & QPOL & Aus \\
\hline Cross border fraud & L2G2BT & USA & Online relationship & QPOL & Aus \\
\hline Romance scheme & L2G2BT & USA & Charity scam & QPOL & Aus \\
\hline
\end{tabular}

Table 8: Scam genre 3

\begin{tabular}{|l|c|c|}
\hline \multicolumn{1}{|c|}{ Scam Name } & Source & Country \\
\hline \hline Business opportunity & SW & AUS \\
Guaranteed employment \& income & SW & Aus \\
Work from home & SW & AUS \\
Transferring money for someone else & SW & AUS \\
Employment or business opportunities & IC3 & USA \\
Re-shipping & IC3 & USA \\
Third party receiver of funds & IC3 & USA \\
Employment work from home & ERG & Can \\
Cheque cashing money transfer job fraud & ERG & Can \\
Work at home \& business opportunity scams & OFT & UK \\
Work at home scams & OGO & USA \\
Job scams & L2G2BT & USA \\
Counterfeit money orders & L2G2BT & USA \\
Bogus business opportunities & USC & USA \\
Work from home & ACCC & AUS \\
Guaranteed employment & ACCC & AUS \\
Phony job opportunities & USPIS & USA \\
Postal job scams & USPIS & USA \\
Work at home schemes & USPIS & USA \\
Employment work from home & SS & AUS \\
Money transfer & SS & AUS \\
Fake job email or money transfer schemes & FIDO & AUS \\
\hline
\end{tabular}

Table 9: Scam genre 4

\begin{tabular}{|l|c|c|}
\hline \multicolumn{1}{|c|}{ Scam Name } & Source & Country \\
\hline \hline SMS compettion \& trivia & SW & Aus \\
Missed calls \& text messages from unknown numbers & SW & AUs \\
Ring tone & SW & AUs \\
Modem jacking & SW & AUs \\
Superannuation & SW & AUs \\
Premium rate prize draw & OFT & UK \\
Property investment & OFT & UK \\
Internet dialer & OFT & UK \\
Bogus vanity publishers & OFT & UK \\
Bogus invention promotions & OFT & UK \\
Bogus model \& casting agencies & OFT & UK \\
Loan scams & OFT & UK \\
Missed calls & ACCC & AUs \\
Text messages & ACCC & AUs \\
SMS compettion \& trivia & ACCC & AUs \\
Faxback & ACCC & AUs \\
Office supply & ACCC & AUs \\
\hline
\end{tabular}

Table 10: Scam genre 5

\begin{tabular}{|c|c|c|}
\hline Scam Name & Source & Country \\
\hline Spyware \& key-loggers & SW & Aus \\
\hline Free offers on the internet & SW & Aus \\
\hline Credit card & SW & Aus \\
\hline Phony fraud alerts & SW & Aus \\
\hline Requests for account information & SW & Aus \\
\hline Credit card fraud & IC 3 & USA \\
\hline Debt elimination & IC3 & USA \\
\hline Identity theft & IC 3 & USA \\
\hline Phishing \& spoofing & IC 3 & USA \\
\hline Spam & IC 3 & USA \\
\hline Phishing \& related & ABS & Aus \\
\hline Identity theft & ABS & Aus \\
\hline Impersonation or identity fraud & FBI & USA \\
\hline Phishing & OGO & USA \\
\hline Hacking & L2G2BT & USA \\
\hline Identity theft & L2G2BT & USA \\
\hline Phishing \& spoofing & L2G2BT & USA \\
\hline Spam & L2G2BT & USA \\
\hline Spyware & L2G2BT & USA \\
\hline Discount software offers & usc & USA \\
\hline Phishing email & USC & USA \\
\hline Trojan horse email & USC & USA \\
\hline Virus generated email & usc & USA \\
\hline Phishing & $\mathrm{ACCC}$ & Aus \\
\hline Fake fraud alerts & $\mathrm{ACCC}$ & Aus \\
\hline Spam & $\mathrm{ACCC}$ & Aus \\
\hline Malicious software & $\mathrm{ACCC}$ & Aus \\
\hline Identity theft & SS & Aus \\
\hline Phishing & SS & Aus \\
\hline Software & SS & Aus \\
\hline Virus & SS & Aus \\
\hline Trojan & SS & Aus \\
\hline Ransom-ware & SS & Aus \\
\hline Spyware & SS & Aus \\
\hline Malware & SS & Aus \\
\hline Fake bank emails & FIDO & Aus \\
\hline Social networking fraud & FIDO & Aus \\
\hline Identity theft & FIDO & Aus \\
\hline
\end{tabular}


Table 11: Scam genre 6

\begin{tabular}{|l|c|c|}
\hline Scam Name & Source & Country \\
\hline \hline Online auction \& shopping & SW & Aus \\
Card skimming & SW & AUs \\
Product misrepresentation & IC3 & USA \\
Non delivery & IC3 & USA \\
Auction fraud Romania & IC3 & USA \\
Parcel courier email scheme & IC3 & USA \\
Escrow services fraud & IC3 & USA \\
Bill for unsuitable merchandise & ERG & Can \\
Medical equipment fraud & FBI & USA \\
Services not performed & FBI & USA \\
Medicare fraud & FBI & USA \\
Debt elimination & L2G2BT & USA \\
Non-delivery & L2G2BT & USA \\
Misrepresentation & L2G2BT & USA \\
Triangulation & L2G2BT & USA \\
Fee stacking & L2G2BT & USA \\
Black market or counterfeit goods & L2G2BT & USA \\
Shill bidding & L2G2BT & USA \\
International auction fraud & L2G2BT & USA \\
Escrow services scam & L2G2BT & USA \\
Card skimming & ACCC & Aus \\
Online auctions \& shopping & ACCC & Aus \\
Ringtone & ACCC & Aus \\
Online classifieds & SS & Aus \\
\hline
\end{tabular}

Table 12: Scam genre 7

\begin{tabular}{|l|c|c|}
\hline Scam Name & Source & Country \\
\hline \hline Identity theft & SW & Aus \\
Computer prediction software & SW & Aus \\
Investment seminars \& real estate & SW & Aus \\
Share promotions \& hot tips & SW & Aus \\
Pyramid schemes & SW & Aus \\
Investment fraud & IC3 & USA \\
Ponzi or pyramid & IC3 & USA \\
Get rich quick & OFT & UK \\
Bogus racing tipster & OFT & UK \\
Pyramid selling \& chain letter & OFT & UK \\
Internet matrix scams & OFT & UK \\
Redemption strawmen or bond & FBI & USA \\
Ponzi scheme & FBI & USA \\
Pyramid schemes & FBI & USA \\
Investment schemes & OGO & USA \\
Ponzi or pyramid & L2G2BT & USA \\
419 advance fee fraud & USC & USA \\
Pyramid scheme & ACCC & Aus \\
Investment seminar & ACCC & Aus \\
Charity & ACCC & Aus \\
Multilevel marketing & USPIS & USA \\
Affinity fraud & SS & Aus \\
Pyramid & SS & Aus \\
Ponzi & SS & Aus \\
Courses \& seminars & SS & Aus \\
Pump \& dump & FIDO & Aus \\
Pyramid schemes & FIDO & Aus \\
Ponzi scheme & FIDO & Aus \\
Affinity fraud & FIDO & Aus \\
Business opportunity & QPOL & Aus \\
\hline
\end{tabular}

\section{ACKNOWLEDGMENT}

This research was funded by the State Government of Victoria, IBM, Westpac, the Australian Federal Police and the University of Ballarat.

\section{REFERENCES}

[1] G., Wahlert, "Crime in cyberspace: Trends in computer crime in Australia," presented at the Internet Crime Conference, Melbourne, Australia, 1998.

[2] A., Stabek, S., Brown, and P., Watters, "The case for a consistent cyberscam classification Framework," in First Cybercrime and Trustworthy Computing Workshop, 2009.

[3] Australian Centre for Policing Research and the Australian Transaction Reports and AnalysisCentre Proof of Identity Steering Committee, "Standardisation of definitions of identity crime terms: A step towards consistency," 145.3, Commonwealth of Australia, 2006.

[4] Australian Bureau of Statistics, "Personal fraud, 2007," No. 4528.0, Australian Capital Territory, 2008.

[5] Parliamentary Joint Committee on the Australian Crime Commission, "Cybercrime," Australian Capitol Territory, 2004

[6] H., Hays, and T., Prenzler, "Profiling fraudsters Queensland case study in fraudster crimes," Final Report to Crime Prevention Queensland, 2002

[7] K.R., Choo, R.G., Smith and R. McCusker, "Future directions in technology-enabled crime: 2007-2009," the Australian Institute of Criminology, No. 78, Australian Capitol Territory, 2007.

[8] Internet Crime Complaint Center, "2007 Internet Crime Report," USA: National White Collar Crime Center, Bureau of Justice Assistance, and the Federal Bureau of Investigation, 2008.

[9] Internet Crime Complaint Center, "2008 Internet Crime Report," USA: National White Collar Crime Center, Bureau of Justice Assistance, and the Federal Bureau of Investigation, 2009.

[10] Model Criminal Law Officers' Committee of the Standing Committee of Attorneys - General, "Final report on identity crime," Australian Capital Territory, 2008.

[11] United Kingdom Office of Fair Trading, "Research on the impact of mass marketed scams," OFT883, Crown Copyright, 2006.

[12] H., Chen, W., Chung, J.j., Xu, G., Wang, Y., Qin, and M., Chau, "Crime data mining: A general framework and some examples," IEEE Computer Society, pp 50-56, 2004.

[13] G., Farrell, K., Clark, D., Ellingworth and K., Pease, "Of targets and supertargets: A routine activity theory of high crime rates," The Internet Journal of Criminology, 2005. Available: www.internetjournalofcriminology.com [Accessed March 2, 2009].

[14] K., Choi, "Computer crime victimization and integrated theory: An empirical assessment," International Journal of Cyber Criminology, volume 2, No. 1, pp. 308 - 333, 2008

[15] A., Stabek, "The effectiveness of using static features in identifying scam genres," M.M.S thesis, University of Ballarat, Ballarat, Australia, 2010. 